\title{
MÉTODO HISTORÍSTICO: DA ANÁLISE EPISTEMOLÓGICA À TÉCNICA E ANÁLISE HISTORÍSTICA
}

\author{
Carlos Roberto FERNANDES*
}

*Enfermeiro, Mestre em Enfermagem, Doutorando em Enfermagem, Professor Assistente na Universidade Federal do Espírito Santo, Departamento de Ciências da Saúde do Centro Universitário Norte do Espírito Santo, São Mateus - ES. Email: crfernandes-enf1@hotmail.com

\section{Recebido em: 25/10/2013 - Aprovado em: 20/12/2013 - Disponibilizado em: 15/01/2014}

\begin{abstract}
Resumo: A identidade entre Ciências Experimentais e Ciências Humanas e Sociais é a utilização dos mesmos processos lógicos ou mentais básicos; as Experimentais investigam fenômenos e as Humanas e Sociais investigam fatos da realidade histórica. Por tal diferença, não impedidora de diálogo e trocas de saberes, há formas de entendimento e de conhecimento complementares e não de compatibilidade e complementaridade de teorias e métodos. Para entender um tipo específico de produção de conhecimentos e de saberes não fenomênicos e objetivados em letra impressa, propõe-se um novo método e uma base teórica à luz do Sistema de Dilthey no qual História é base intransponível para os sistemas culturais e sistemas de organização interna e externa da sociedade. OBJETIVO: explicitar a constituição do Método Historístico para análise epistemológica da procedência de conhecimentos em textos escritos e para formação de novos saberes. MÉTODO: Pesquisa Metodológica, de abordagem e de análise epistemológica para explicitação de um novo Método denominado Historístico e consequente técnica historística. RESULTADOS: Pelo diálogo com o Historismo e a Hermenêutica de Dilthey, cria-se constructos de análise epistemológica para determinar a proveniência (e não origem) das multivariadas concepções de mundo inerentes e nem sempre evidentes aos conhecimentos produzidos e impressos. Da abordagem e análise epistemológica chega-se à proposição da Historística e do Método Historístico. CONCLUSÃO: Historística é campo de formação de saberes. Dois possíveis usos do Método Historístico é de entendimento (conhecimento do já conhecido) e de formação de novos saberes, derivados ou não de conhecimentos escritos (impressos) já postos.
\end{abstract}

Palavras-Chave: Método. Metodologia. História. Epistemologia. Ciência.

\section{HISTORISTIC METHOD: OF THE EPISTEMOLOGICAL ANALYSIS TO TECHNICAL AND ANALYSIS HISTORÍSTICA}

\begin{abstract}
The identity of Experimental Sciences and Humanities and Social Sciences is the use of the same basic logical processes or mental; investigate the experimental phenomena and Human Social investigate the facts of historical reality. Why such a difference, not blocking for dialogue and exchange of knowledge, there are ways of understanding and knowledge of complementary and non-compatibility and complementarity of theories and methods. To understand a specific type of knowledge production and knowledge not phenomenal and objectified in print, we propose a new method and a theoretical basis in the light of System Dilthey in which history is based insurmountable cultural systems and systems internal and external organization of society. OBJECTIVE: To clarify the constitution of Historístic Method for epistemological analysis of the merits of knowledge in written texts and training of new knowledge. METHOD: Research Methodology, approach and epistemological analysis for explanation of a new method called Historístic and consequent technical historística. RESULTS: At dialogue with Dilthey's Hermeneutics and Historism, it creates constructs of epistemological analysis to determine the provenance (not origin) of multivariate worldviews inherent and not always obvious to the knowledge produced and printed. Approach and epistemological analysis arrives at the proposition of Historística and Method Historistic. CONCLUSION: Historística is field training knowledge. Two possible uses of the method is Historistic of understanding (knowledge already known) and the formation of new knowledge, or not derived of knowledge written (printed) already put.

Keywords: Methods. Methodology. History. Epistemology. Science.

\section{MÉTODO HISTORÍSTICO: DE LA ANÁLISIS EPISTEMOLÓGICA A LA TÉCNICA Y ANÁLISIS HISTORÍSTICA}

\begin{abstract}
Resumen: La identidad de Ciencias Experimentales y Humanidades y Ciencias Sociales es el uso de los mismos procesos lógicos básicos o mentales, investigar los fenómenos experimentales y sociales Humanos investigar los hechos de la realidad histórica. ¿Por qué tanta diferencia, no impedidora el diálogo y el intercambio de conocimientos, hay formas de entendimiento y conocimiento de la complementariedad y la no compatibilidad y complementariedad de las teorías y métodos. Para entender un tipo específico de producción de conocimiento y el conocimiento no es fenomenal y objetivada en la impresión, se propone un nuevo método y una base teórica a la luz del sistema de Dilthey en que la historia se basa sistemas culturales insuperables y sistemas organización interna y externa de la sociedad. OBJETIVO: Para aclarar la constitución de Historístico Método para el análisis epistemológica de los méritos de los conocimientos de los textos y la


formación de nuevos conocimientos por escrito. MÉTODO: Investigación Metodológica, el planteamiento y análisis epistemológica para la explicación de un nuevo método Historístico y consecuente técnica historística. RESULTADOS: En diálogo con la hermenéutica y el historismus de Dilthey, crea construcciones de análisis epistemológica para determinar la procedencia (no origen) de las cosmovisiones multivariados inherentes y no siempre es obvio para el conocimiento producido e impreso. Enfoque y análisis epistemológica llega a la proposición de Historística y método Historístico. CONCLUSIÓN: Historística es el conocimiento entrenamiento de campo. Dos posibles usos del método Historístico es lo entendimiento (conocimiento que ya se conoce) y la formación de nuevos conocimientos, o no derivado de los conocimientos por escrito (impreso) ya puestos.

Palabras clave: Método. Metodología. Historía. Epistemología. Ciencia.

\section{INTRODUÇÃO}

Análise, Método e Epistemologia são termos cotidianos no mundo acadêmico: antes de se debruçar sobre as várias (e não raro divergentes) concepções de mundo sobre o que é Epistemologia, Análise e Método, em geral os acadêmicos tem uma mística certeza de que não há mais nada a dizer sobre tais questões; no entanto, não é cabível tal certeza com e a partir de Giambattista Vico (1668-1744), de Wilhelm Dilthey (1833-1911), de Friedrich Nietzsche (1844-1900), de Michel Foucault (1926-1984), de Jacques Derrida (1930-2004).

O filósofo napolitano Vico contrapõe-se ao Racionalismo ou Cartesianismo e apresenta a sua La Scienza Nuova publicada em 1725, erguida no princípio verum ipsum factum (verdadeiro, é o feito ou verdade é o fato). Com tal princípio tipifica o conhecimento em: a) filosofia (até o século XVIII filosofia era ciência), reveladora do verum, do verdadeiro; b) consciência ou conhecimento externo, fora do mundo humano e revelador do certum; c) revelação ou conhecimento dos padrões, das verdades eternas e dos princípios; d) histórico ou conhecimento interno, fundado no autoconhecimento das atividades, dos esforços, dos propósitos, dos valores e das atitudes humanas). Vico faz clara distinção entre conhecimento externo e interno - o que posteriormente tornar-se-ia na distinção entre ciências da natureza (campo do certum, do explicar) e ciências humanas (campo do verum, do compreender). Anticartesiano, coloca a História no centro das ciências e da qual Filosofia (= a Ciência) e Filologia (= Arte Crítica) são as disciplinas básicas. (VICO, 1959)

A Ciência Nova de Vico influenciará vários filósofos e historiadores do século XIX e $\mathrm{XX}$, entre os quais Franz Clemens Honoratus Hermann Brentano (1838-1917) e Wilhelm Dilthey.

Primeiro e principal teórico da Escola Histórica Alemã, Dilthey contrapõe-se ao Positivismo de Augusto Comte e ergue o edifício autônomo lógico, epistemológico e metodológico das Ciências do Espírito (hoje, Humanas e Sociais): eliminando a litania entre dedução e indução, sujeito e objeto, funda o princípio da Vivência estudável (compreensível) nas expressões da vivência (o espírito objetivado ou manifestações de vida); considerando que a diferença entre as ciências da natureza e ciências do espírito não está nos processos lógicos elementares, utilizadas por ambos os grupos de ciências, retoma o verum e 
o certum de Vico para diferenciar os processos de compreender e de explicar daqueles grupos.

O Historismo de Dilthey, igualmente colocando a História no centro de todas as demais ciências, influencia quase todo o pensamento do século XX - de Georg Simmel (1858-1918) a Jürgen Habermas.

Tanto em Vico quanto em Dilthey, análise significa não-lise, ou seja, não é processo de decomposição.

Nietzsche é o demolidor de tudo quanto foi erguido no mundo ocidental a partir de Sócrates: aliás, para o filósofo alemão a Filosofia nasce com os pré-socráticos e morre com o último deles. O assassino e o coveiro da Filosofia é Sócrates e todos os que vieram com ele e depois dele: Nietzsche (1998), para o qual conhecimento significa invenção (erfindung), cria um caminho (genealógico) pelo qual demonstra a fantasia da origem (ursprung) e a mentira (da filosofia e da ciência ocidental) na busca de uma verdade (inexistente).

Foucault, influenciado por Nietzsche, tanto utiliza a sua genealogia quanto propõe a arqueologia para investigar as formações discursivas emergentes (entestehung) das quais procedem (herkunft) os saberes-poderes humanos. Para livrar-se dos conceitos de ciência, de ideologia, Foucault literalmente faz historismo ou, conforme sua linguagem, arqueologia dos saberes - explicitando as epistémês (clássica, renascentista e moderna) provenientes (herkunft) de uma microfísica do poder.
A desconstrução do filósofo francoargentino Derrida é a última consequência contemporânea do pensamento de Vico (para quem a história das nações ou do mundo civil é história da linguagem) e de Dilthey (para quem toda Filosofia e Ciência são empíricas porque procedem da Vivência (Erlebnis) e, portanto, são filosofias e ciências da experiência íntima ou interna, fixadas em concepções de mundo de seus criadores. Para Derrida não existem fatos mas interpretações geradas pelas concepções de seus intérpretes: é a mesma concepção de Dilthey em nova roupagem. Nietzsche, Martin Heidegger e Sören Kierkegaard (e não declaradamente Vico e Dilthey) são influências marcantes em Derrida que, a exemplo de todos os filósofos citados, condena a centralidade e a mística ocidental do Lógos.

A obra-referência de Derrida intitula-se Gramatologia, publicada em 1967 e na qual há drástica redução (senão o fim) de toda a pretensão da (s) ciência (s) positiva (s): a crise da linguagem, evidente na proliferação de disciplinas e discursos sobre linguagem, é o sintoma desconstrutivo do conceito linguagem (enclausurada no pensamento fonocêntrico, logocêntrico e metafísico ocidental) para o conceito de écriture (escritura) como "jogo do mundo" (e não no mundo) na linguagem. A écriture deixa de ser um epifenômeno da linguagem: é preciso deixar-se abalar e acolher a écriture (o jogo do mundo) para depois compreender as multiformas de jogo no mundo (o suposto sentido). Um dos movimentos dessa desconstrução é livrar-se (da), superar a 
Linguística de Ferdinand de Saussure com a ideia de signo e a oposição entre significado e significante. (DERRIDA, 2002; DERRIDA, 2008)

A desconstrução de Derrida, opondo-se inclusive ao Estruturalismo, não é demolição mas deslocamento, desenraizamento, desmontagem primeiramente do logos como origem (ursprung) da verdade e, consequentemente de desmontagem da arquitetura conceitual nas "falsas unidades verbais" da Filosofia (ou da Ciência) Metafísica Ocidental entre as quais estão os dualismos (e, também, dicotomias) verdade pensamento, sensibilidade - inteligibilidade, pensamento - linguagem, sentido - signos, significante - significado, palavra - escritura, corpo - alma, interior - exterior, essência aparência, verdadeiro - falso, dentro - fora, superior - inferior. A desconstrução não é (e nunca deverá ser) um método: com ela é preciso romper o tímpano dos filósofos $\mathrm{e}$ filosofar é filosofar com o martelo. Eis, nas devidas proporções, a proximidade entre Nietzsche e Derrida. (DERRIDA, 1993; CONTINENTINO, 2006)

A palavra epistemologia surge em 1854, inventada pelo filósofo escocês James Frederick Ferrier (1808-1864): sua principal obra intitula-se Institutes of metaphysics: The theory of knowing and being, na qual divide a Filosofia em Epistemologia e Ontologia. Na proposição de Ferrier (1854, p.46), Epistemologia é a doutrina ou a teoria do
Conhecimento e Ontologia é a doutrina ou teoria do ser.

Antes de Ferrier, Teoria do Conhecimento - subcampo da Filosofia preocupava-se com a possibilidade, a origem, o limite, a essência, as formas e o valor do conhecimento, enquanto a Gnoseologia também subcampo da Filosofia - preocupava-se com a validade do conhecimento com relação ao sujeito cognoscente.

O filósofo Valentin Fromme (16011675) foi o primeiro a utilizar-se da palavra gnoseologia no ano de 1631 para referir-se a questões relativas ao conhecimento. Gnoseologia era uma disciplina da Metafísica e por influência da Escolástica designava, em geral, teoria do conhecimento. (FAITANIN, $\mathrm{s} / \mathrm{d})$

Com o nome de Epistemologia, Ferrier suprimiu a doutrina ou teoria do conhecimento como campo autônomo para tornar-se o objeto de estudo daquela.

Nas línguas espanhola e italiana, o termo gnoseologia é utilizado mais frequentemente; em alemão é mais comum o uso da expressão Erkenntnistheorie (Teoria do Conhecimento) e menos frequentemente a expressão Erkenntniskritik (Crítica do Conhecimento); em inglês é mais utilizado o termo Epistemology; em francês utilizam-se Théorie de la connaissance, Gnoséologie, Épistémologie.

Nesta investigação utilizar-se-á o termo epistemologia para significar o estudo analítico-crítico da proveniência (herkunft), a invenção (erfindung) e a emergência 
(entestehung) de saberes e de conhecimentos.

As palavras alemãs herkunft, erfindung e entestehung são utilizadas por Friedrich Nietzsche e por Michel Foucault para referir-se a genealogia e a arqueologia do saber, sem a noção metafísica de origem ou fundamento originário (ursprung) do saber ou do conhecimento como se existisse um ente luminoso e certo (a verdade) cuja essência deve ser descoberta (pelo conhecimento); portanto, quando Fernandes (2003) criou um método de análise epistemológica para abordagem epistemológica dos saberes impressos e publicados em dissertações, teses e artigos científicos a concepção genealógica de proveniência, de invenção e de emergência daqueles saberes.

\section{A proveniência (herkunft) designa o}

pertencimento a um grupo - do sangue, da tradição, de ligação entre aqueles da mesma altura ou da mesma baixeza. [...] Entretanto, não se trata de modo algum de reencontrar em um indivíduo, em uma ideia ou um sentimento as características gerais que permitem assimilá-los a outros - e de dizer: isto é grego ou isto é inglês; mas de descobrir todas as marcas sutis, singulares, subindividuais que podem se entrecruzar nele e formar uma rede difícil de desembaraçar." Ainda na mesma referência, Foucault explicita: a proveniência é uma herança, não no sentido de acumulação solidificada, mas acumulação "de falhas, de fissuras, de camadas heterogêneas que a tornam instável, e, do interior ou de baixo, ameaçam 0 frágil herdeiro. (FOUCAULT, 2012, p. 20-1)

Eis porque a proveniência refere-se a tudo existente no corpo porque é do corpo, pelo corpo e no corpo que se faz história. (FOUCAULT, 2012) Talvez por isso e anteriormente à genealogia de Nietzsche e a arqueologia de Foucault, Wilhelm Dilthey demonstra que Teoria do Conhecimento é psicologia (descritiva e analítica e não explicativa ou experimental) em movimento. (Dilthey, 1951)

A invenção (erfindung) opõe-se à origem (ursprung) e em Nietzsche (1998) significa conhecimento - inventado mediante rupturas entre relações de poder, insignificantes começos mesquinhos e não confessáveis. Eis a produção de conhecimento - a invenção da verdade.

A emergência ou gênese (entstehung) de "um a partir do outro" é um processo vagaroso de formação (bildung), expressando espaços de enfrentamento, luta, jogo e tensão entre forças e ameaças em que deixa para trás um rastro de vencidos ou excluídos. (FOUCAULT, 2012)

Com tais esclarecimentos prévios e sintéticos, ao método de análise epistemológica para abordagem epistemológica Fernandes (2003), Fernandes e Nascimento (2005) e Fernandes (2010) posteriormente denominam de Historística ou Método Historístico.

\section{OBJETIVO}

- explicitar a constituição do Método Historístico para análise epistemológica da procedência de conhecimentos em textos escritos e para formação de novos saberes.

\section{RESULTADOS}

Para conhecer-entender-compreenderesclarecer a proveniência de saberes registrados 
em uma obra escrita, o autor parte do diálogo com alguns conceitos do Sistema de Dilthey.

A - Conceitos básicos

Os conceitos básicos do Historismo de Dilthey não se resumem à razão histórica, crítica da razão histórica e consciência histórica: no entanto, considera-se os mesmos fundantes do Historismo de Dilthey.

\section{Razão histórica traduz o fato de que}

O homem individual, como ser isolado, é mera abstração. $\mathrm{O}$ parentesco de sangue, a convivência local, a cooperação no trabalho, na competência e no esforço comum, as múltiplas conexões que se produzem da prosecução comum dos fins, as relações de poder no mando e a obediência, fazem do indivíduo membro da sociedade. Como esta sociedade se compõe de indivíduos estruturados, nela operam também as mesmas regularidades estruturais. A teleologia subjetiva e imanente dos indivíduos se manifesta na história como desenvolvimento. As regularidades psico-individuais transformam-se em regularidades da vida social. (DILTHEY, 1954, p.35)

O conceito diltheyano de razão histórica diz que o eu, a inteligência, o pensamento, a individualidade, junto a todas as faculdades ou processos mentais, são formações históricas:

A inteligência não é um desenvolvimento do indivíduo isolado, algo que pudesse ser compreensível a partir dele mesmo, mas é um processo no âmago da evolução do gênero humano e no qual a vontade de conhecimento se dá neste mesmo sujeito. (DILTHEY, 1986, p.90)

\section{Crítica da razão histórica, ao superar a} razão metafísica de tanto de Platão quanto de Aristóteles e a razão pura de Kant, se define como capacidade do homem e da mulher se (re)conhecerem históricos e de (re)conhecerem que a história e a sociedade são suas formações. (DILTHEY, 1986, p.29)

O Historismo de Dilthey declara o fim da Metafísica, erguida de Sócrates-PlatãoAristóteles à Augusto Comte: sem negar a construção dessa Metafísica e o seu papel amadurecedor do pensamento europeu ocidental (=a metáfora para significar mundo platônico-aristotélico) quanto ao mundo empírico-experimental, o Historismo limita esse mundo ao estudo dos nexos causais da natureza ou dos fenômenos pelas Ciências da Natureza ou Experimentais e congrega o estudo dos nexos do mundo histórico e não fenomênico ao campo da Ciências do Espírito ou Experienciais:

-à crítica da razão pura Guillermo Dilthey contrapõe a crítica da razão histórica para análise hermenêutica das condições do conhecimento na consciência histórica e, com esse ato historista, ergue a Epistemologia Histórica;

-à crítica da razão teórica contrapõe a crítica histórica da razão para análise hermenêutica das condições históricas do conhecimento e, com esse ato historista, ergue a Filosofia $d a$ Vida, da Experiência, da Empiria - o sistema filosófico superador do racionalismo, do empirismo e do transcendentalismo;

-à crítica da razão prática contrapõe a autognose histórica para análise hermenêutica das condições da consciência histórica no conhecimento e, com esse ato historista, ergue a Psico-história - uma psicologia analítica e descritiva do homem e da mulher históricos. 
Ratificando: crítica da razão histórica é consciência histórica quando tem por referência analítico-descritiva as expressões da vivência, também nomeadas por Wilhelm Dilthey de manifestações ou concretizações da vida, espírito objetivado; é autognose histórica quando tem por referência analítico-descritiva a própria consciência histórica.

Num parêntese explicativo, do conceito diltheyano de autognose histórica fundadora da Psicologia Histórica, posteriormente Carl Gustav Jung ergue o método construtivo (ou sintético) da sua Psicologia Analítica para a teoria histórico-racial da psique humana; Sigmund Freud ergue o conceito e a prática metodológica de psicanálise para sua teoria psicossexual da personalidade e Eric Hombourger Ericson (1902-1994) ergue o seu método denominado psico-história para a teoria psicossocial da personalidade e do comportamento humano: se a hermenêutica para Dilthey interconecta antropologia psicologia história, o método ericsoniano de psico-história interconecta psicanálise e história, o método sintético junguiano interconecta Dilthey e Vico, o método psicanalítico interconecta psiquiatria e sexologia.

Consciência histórica é uma das dimensões da própria crítica da razão histórica.

Tanto o (re)conhecimento da historicidade da consciência humana quanto do mundo social formados pelas pessoas (sempre históricas), formam a consciência histórica.
Consciência histórica é conhecimento

das

grandes objetividades engendradas pelo processo histórico, dos nexos finais da cultura, das nações, da humanidade mesma, da formação em que se desenvolve a vida, segundo uma lei interna [; aquelas grandes objetividades e nexos finais] atuam como forças orgânicas, de onde surge a história das lutas de poder dos estados. (DILTHEY, 1949, p.11)

Razão histórica, consciência histórica, crítica da razão histórica revolucionam o próprio conceito e método da História pela consciência científico-experiencial, científicoespiritual ou científico-hermenêutica sem a qual a própria memória histórica é silenciada ou desqualificada.

B - Conceitos integrantes e correlatos

Tais conceitos são denominados integrantes e estão inclusos nos próprios conceitos básicos; denominam-se correlatos aqueles que decorreram de investigações de Fernandes (2003) à luz do Historismo de Dilthey. Aqui, destacam-se apenas os conceitos correlatos de memória histórica e de consciência metodológica.

Com a análise hermenêutica, o desenrolar metodológico da crítica da razão histórica caracteriza a consciência científicoespiritual, assim definida por Dilthey:

$\mathrm{Na}$ correlação constante das vivências e dos conceitos [até se alcançar a] consciência científico-experiencial [, na qual] não deve haver nenhum conceito que não se tenha formado em toda a plenitude do reviver histórico; não deve haver nada geral que não seja a expressão essencial de uma realidade histórica. [...] Acima de toda representação e estilização do real e do singular, o pensamento esforça-se para chegar ao 
conhecimento do essencial e necessário; aspira a compreender a conexão estrutural da vida individual e social; porque somente conquistaremos poder sobre a vida social, quando captarmos e aproveitarmos sua regularidade e conexões. As formas lógicas em que se expressam essas regularidades são juízos [ou conceitos gerais] cujos sujeitos são tão gerais como seus predicados.

Entre os múltiplos conceitos gerais do sujeito, ao serviço desta tarefa nas ciências do espírito [ou da vida], encontram-se alguns como filosofia, arte, [ciência], religião, direito, economia. (DILTHEY, 1952, p.76-7)

A definição diltheyana de consciência científico-espiritual, consciência científicoexperiencial, expressa os fundamentos do que pode ser denominado de consciência metodológica.

O desenrolar metodológico da crítica da razão histórica, caracterizadora do que pode ser denominado consciência metodológica (consciência hermenêutica ou historística), consiste em dois movimentos hermenêuticos (historísticos) básicos:

$1^{o}$. movimento. correlacionar conceitos $\mathrm{e}$ vivências formadas na expressão fundamental e necessária, especial e geral, importante e valorativa do mundo histórico.

O princípio determinante do que é fundamental (um princípio da Estética), necessário (um princípio da Poética), especial (um princípio da Arte), geral (um princípio da Práxis), importante e valorativo (princípio da Ética) deve ser buscado na regras radicais do Historismo e do Empirismo Histórico:

-Primeira regra de Giambattista Vico: verdadeiro é o feito, verdade é o fato, verum ipsum factum. Vico rompe com a tradição metafísica de que verdade ou o verdadeiro é o argumento (argumentos sobre fatos) ou a sua justificação;

-Segunda regra de Dilthey (1986): o pensamento não pode ir além da vida, ou seja além do mundo histórico, porque esse mesmo pensamento se forma e se desenvolve no mundo histórico porque a razão é histórica.

São dois princípios desconstrutores da suposta supremacia da razão cartesiana, da razão pura kantiana, da verdade da argumentação e da verdade do método na ciência moderna.

As Ciências do Espírito (humanas e sociais) não buscam uma suposta verdade, evidenciada pelo argumento nem aquela revelada pelo método e muito menos prova ou evidência disso ou daquilo porque para a Escola Diltheyana de Pensamento a vida, o mundo histórico é sua própria demonstração: buscam o essencial e o necessário do fato histórico ou, simplesmente, do fato, do feito, do realizado, do vivido.

$2^{\circ}$. movimento. compreender a conexão estrutural da vida individual e social.

Não é nenhuma genialidade autônoma ou vontade de saber de uma pessoa que cria os conceitos gerais de filosofia, arte, ciência, religião, direito, economia efetua a compreensão, mas a própria estrutura psicofísica dessa pessoa que é histórica; não são as uniões lógicas artificiosas, criadas por cada um dos sistemas seriados ou especializações com os seus métodos e argumentos, que produzem ou promovem nexos, conexões. 
No Pensamento Diltheyano, porque é histórica, a pessoa compreende aquela conexão estrutural porque ela própria é essa conexão estrutural: tal compreensão das regularidades e conexões da vida individual e social é a própria fonte do poder sobre a vida social. Este princípio também está no pensamento de Giambattista Vico quando o filósofo napolitano considera que somente compreendemos o que é criação nossa, ou seja, apenas o mundo histórico; o mundo natural é objeto de conhecimento e não objeto de entendimento.

Os dois princípios hermenêuticos (ou historísticos) são, em verdade, as bases pelas quais propus o conceito de trajetórias $e$ memórias de corpo.

Trajetórias de corpo referem-se às vivências e às experiências de corpo das pessoas, elas mesmas formadoras de comunidades, povos e Estados; constituem, pois, a história e são nomeados, no Historismo de Dilthey, de mar empírico de história, trajetória vital, trajetória de vida - todas expressões sinônimas; do tecido emaranhado da história, formado nesse mar empírico de história também se forma a memória histórica.

Memórias de corpo são as objetivações de trajetórias; constituem, pois, historiografias e são nomeados no Historismo de Dilthey, de expressão da vivência, espírito objetivado, manifestação de vida, objetivação de vida, grandes objetividades do pensamento - todas expressões sinonímias.

Com os conceitos básicos, integrantes e correlatos Fernandes (2003) cria cinco concepções (constructos) para identificar, discriminar e classificar as concepções, possivelmente expressas nas escrituras analisáveis:

-A concepção fluente (coflu) flui das trajetórias e memórias de corpo da pessoa que se quer analisar.

De um modo geral, trajetórias de corpo são a história e memórias de corpo são a historiografia.

-A concepção afluente (caflu) aflui das trajetórias e memórias dos referenciais significativos (teóricos, bibliográficos, metodológicos e demais pessoas, inclusive as possíveis pesquisadas pela pessoa que se quer analisar).

-A concepção influente (cinflu) é a que traduz as concepções do autor que se quer analisar, mas onde se vê que são posteriores às suas próprias vivências e experiências; ou seja, depois de metabolizar as caflus, o autor sob análise expressa concepções, desencadeadas por análise e reflexão das trajetórias e memórias dos referenciais significativos, postas, pospostas ou contrapostas às suas próprias trajetórias e memórias (as coflus).

-A concepção defluente (deflu) deflui das trajetórias e memórias rejeitadas, criticadas, afastadas, descartadas pelo autor que se quer analisar.

-A concepção confluente (conflu) é a síntese não redutiva de todas as anteriores concepções e onde entendo que haverá possível formação e desenvolvimento do saber. 
Pelas cinco concepções, procede-se à análise epistemológica: em primeiro lugar investigam-se as fontes e o alcance dos conhecimentos postos na escritura sob análise; em segundo lugar, formar-se-ão saberes, seguindo ou não as concepções e os conceitos postos na escritura sob análise. Isso significa estabelecer a distinção entre conhecimento e saber.

A trajetória da análise epistemológica realizada expressa o processamento analítico, descrito abaixo em todos os passos seguidos, desde o contato com a escritura. Sem que o leitor e a leitora se sintam obrigados a metabolizar todas as nomeações dadas a cada momento da trajetória, coloco-as para fundamentação e demonstração do próprio processo de desenvolvimento e metabolização da análise.

Primeiro passo: Conhecimento global do conteúdo da escritura.

Segundo passo: Atenção aos conteúdos da escritura e numeração de todos os parágrafos, independente dos títulos, subtítulos, itens e subitens.

Terceiro passo: Destaque das ideias, noções, comentários e concepções sobre o que se quer analisar, chamadas proto-unidades vivenciais (PUVs), de cada parágrafo, donde sairão todos os conteúdos de um tema sob análise.

Quarto passo: As PUVs serão classificadas, segundo a sua origem, e, nesse momento, chamo-as de unidades vivenciais (UVs).
-UVs.RT ou UVs.RB: pertencentes aos referenciais teóricos ou bibliográficos do autor da escritura analisada.

-UVs.PP: pertencentes às pessoas pesquisadas pelo autor da escritura analisada.

-UVs.TP: pertencentes aos autores das escrituras sob análise.

-UVs.CR: referentes às concepções que foram rejeitadas, criticadas e não utilizadas pelo autor da escritura analisada, geralmente elencadas em revisões históricas gerais.

Quinto passo: No agrupamento das UVs, segundo a origem, aplico a classificação das cinco concepções, abreviadamente designadas por COFLUs, CAFLUs, CINFLUs, e DEFLUs. Repito: as coflus e as caflus são as concepções exclusivas daquela área de conhecimento específica, expressões das trajetórias e memórias de corpo dos profissionais/autores e das pessoas com quem interagiram nas relações profissionais/acadêmicas ou assistenciais (se for o caso) ou nas interrrelações com outrem (p.ex., entrevistas, relações terapêuticas...). As conflus são as concepções dos referenciais teóricos e bibliográficos e as cinflus ou valores foram apreendidos em cada uma das outras concepções, exceto às conflus.

Sexto passo: Apreensão dos valores das coflus. Esses valores apreendidos ou conflus e sua origem são as trajetórias e memórias (inquestionavelmente de corpo porque não existe pessoa humana sem corpo) das pessoas pesquisadas, das escrituras sob análise. 
Sétimo passo: Apreensão dos valores das caflus. A rigor, esses valores apreendidos ou conflus procedem das trajetórias $e$ memórias de corpo dos autores analisados.

Oitavo passo: Apesar da origem diferenciada de coflus e caflus, pesquisadores e pesquisados sob análise podem ser ambos profissionais de diferentes (ou não) áreas do conhecimento; portanto, coflus e caflus são expressões de trajetórias e memórias de corpo dos autores analisados. Tem-se dois conjuntos de experiências, cujos valores apreendidos são conflus.

Neste passo, as divisões entre coflus e caflus poderão ser desconsideradas. Consequentemente, as conflus de cada escritura também não foram divididas. Agrupadas, estas conflus são consideradas uma nova escritura ou unidade de vida, que, repetindo, são os valores apreendidos nas coflus e caflus. Realiza-se, então, o agrupamento de todas as conflus, originadas das coflus e caflus, para formação de tipos vivenciais: os tipos vivenciais transformam-se em unidades epistêmicas para formação de tipos epistêmicos.

Unidades vivenciais, Tipos vivenciais, Unidades epistêmicas e Tipos epistêmicos não expressam um movimento para reunir possíveis experiências genéricas, uniformes, regulares e que, por isso, teriam caráter de legalidade e previsibilidade, abrindo campo à constituição de leis gerais sobre trajetórias e memórias de corpo. Esse não é o meu caminho e não é a Epistemologia das Ciências do Espírito (humanas e sociais), embora o seja das
Ciências Naturais. Com esta organização, quero, além de realçar o caráter interconexo de singularidade historicizada ou de historicidade singularizada das trajetórias e memórias de corpo, utiliza-las para a formação de novos saberes: esta conexão não é uma lei geral, mas uma estrutura (dinâmica, vital) ou conexão viva.

O agrupamento das unidades de vida quer explicitar o que Dilthey define como tipo, ou seja, "a forma mais simples segundo a qual a vivência se estrutura num grupo". (DILTHEY, 1951, p.367)

Aclarando a definição de tipo, Dilthey fala da "circunstância notável" percebida por ele quando, diante das infinitas expressões da vivência ou manifestações de vida: apesar da multivariedade destas expressões, os "modos de relação", nestas expressões, "são os mesmos, considerados em grandes grupos: pode-se ordenar estes grupos em torno a um tipo, e este tipo e o subordinado a ele pode-se delimitar com precisão frente a outro tipo". (DILTHEY, 1951, p.367) Se a delimitação é impossível pela infinidade das vivências, suas expressões e objetivações são delimitáveis pelo tipo, ou seja, pela uniformidade dos seus "modos de relação". Eis a historista e diltheyana Teoria do Tipo, posteriormente fundamentadora do Estruturalismo e, também, utilizada por Max Weber e seus tipos ideais, por Carl Gustav Jung e seus tipos psicológicos; pela mesma teoria diltheyana do Tipo ergui os conceitos de tipos vivenciais e tipos epistêmicos. 
Esse trabalho de agrupamento das trajetórias e memórias tem interesse epistemológico.

Nono passo: Agrupamento dos valores das deflus para formação de tipos vivenciais que posteriormente sirvam como unidades epistêmicas para a formação de tipos epistêmicos. Nesse caso, os tipos destacam os temas ou ideias rejeitados pelos profissionais/pesquisadores sob análise.

Décimo passo: Análise pela evidenciação de tendências e perspectivas epistemológicas das memórias de corpo estudadas e expressas em tipos vivenciais e, destes, em tipos epistêmicos.

A análise pode ser realizada em quatro aspectos:

a) na apreensão de "categorias historísticas", expressivas da lógica experiencial ou gnoseológica de Dilthey.

b) amplificação dos tipos vivenciais e tipos epistêmicos.

A amplificação é uma contribuição por mim aceita do método junguiano para análise dos sonhos e dos símbolos, chamado por Carl Gustav Jung de método sintético. Trata-se de, a partir de um ponto central, um símbolo, uma ideia, uma vivência ou concepção, estabelecer analogias sobre analogias, desenvolvidas de forma cíclica ou em espiral e que cada vez mais se aproximem daquele ponto central ou mantenham-se em rotação ou circularidade em torno do centro. (JUNG, 1991)

A amplificatio é eminentemente um método hermenêutico, de multiplicação e ampliação de conteúdos e contextos, buscando o entendimento. Os conteúdos são enriquecidos com material associativo e analógico até a máxima inteligibilidade possível.

Não se referindo a sonhos e símbolos, tomo a amplificação na essencialidade de seu sentido: multiplicar, ampliar, enriquecer, desenvolver os tipos vivenciais e os tipos epistêmicos, de forma analítico-crítica pelo estabelecimento de associações, analogias e de consequências que as próprias unidades vivenciais e unidades epistêmicas permitem. Estas consequências, às vezes, não foram percebidas ou não ditas pelo próprio criador da escritura. Eis a significação do princípio de Friedrich Daniel Ernst Schleiermacher, aceito por Dilthey (1986), de que o intérprete deve entender a escritura mais que o seu próprio autor. Todo esse processo é o movimento de amplificação com o qual busco aproximar-me do que Dilthey considera fundamental para o método conectivo, compreensivo, experiencial ou hermenêutico-crítico das ciências da vida: “compreensão de toda individualidade histórico-humana a partir da conexão e a comunidade de toda vida psíquica [...] mediante um enlace intelectual de experiências". (DILTHEY, 1986, p.251)

c) apreensão de perspectivas, tendências epistemológicas dos tipos vivenciais diante do conhecimento já constituído. Essa apreensão tem por objetivo desenvolver um campo de saber específico dos terapeutas do corpo e do cuidado. 
d) apreensão ou formação de unidades epistêmicas e tipos epistêmicos para a construção e desenvolvimento de novos saberes.

O diagrama de todo o processo de análise epistemológica pode ser assim expresso:

Diagrama 1: Esquema Analítico

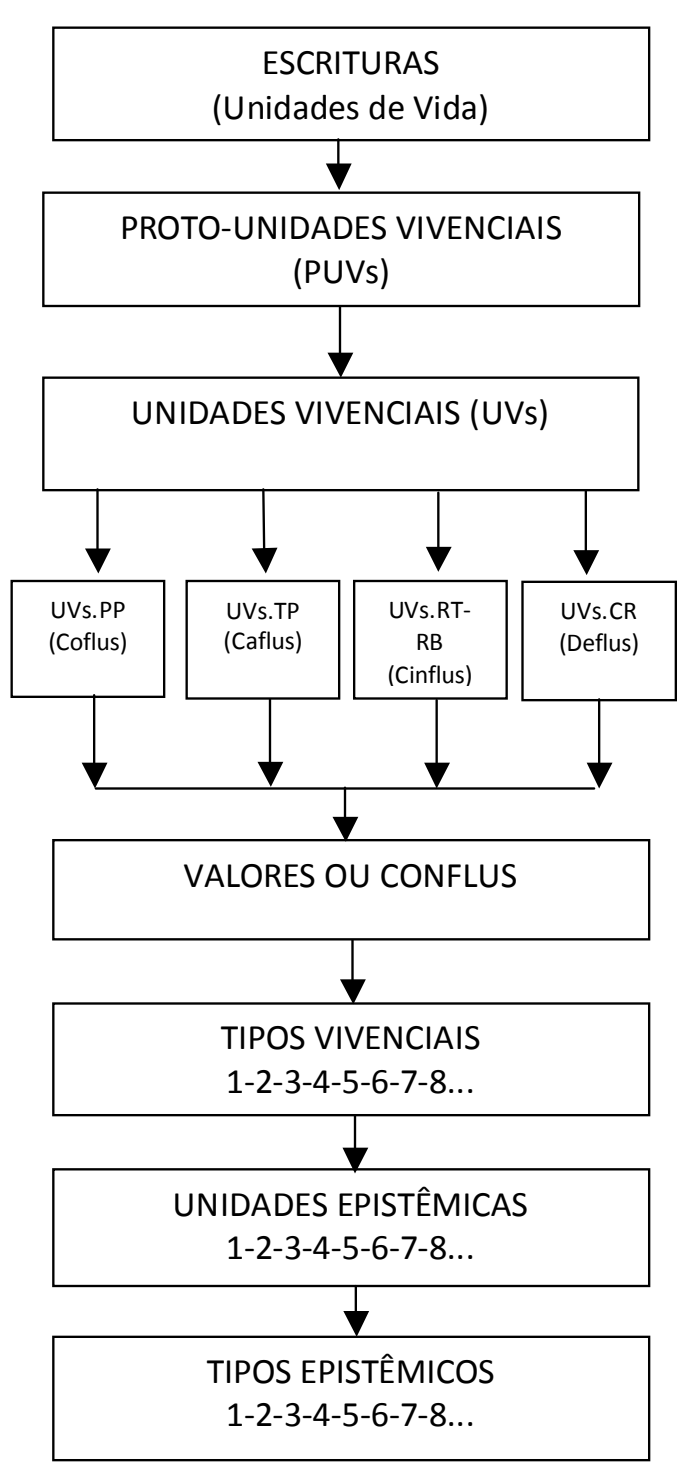

Fonte: o Autor

Pelo diálogo com o Historismo de Dilthey e com o pensamento da Ciência Nova de Vico propôs-se a Historística - respeitando- se as trajetórias e memórias do autor (homem latino-americano), nela inclusa a profissão de enfermeiro, e para a qual há metabolização da significação de consciência científicoexperiencial - agora nominada de consciência historística, herdeira da consciência e da racionalidade hermenêutica. (FERNANDES e NASCIMENTO, 2005)

Aquela análise epistemológica do início das pesquisas de Fernandes (2003), profundizada com o pensamento historista e hermenêutico, desenvolveu-se a proposta de análise historística por Fernandes (2010) para fins determinados; ou seja, a análise historística não se presta APENAS para a determinação da proveniência de saberes num documento escrito, mas é mais um dos recursos heurísticos onde a intenção não é análise de discurso, análise de ideias, análise de conteúdo:

Diagrama 2: Atos Historísticos

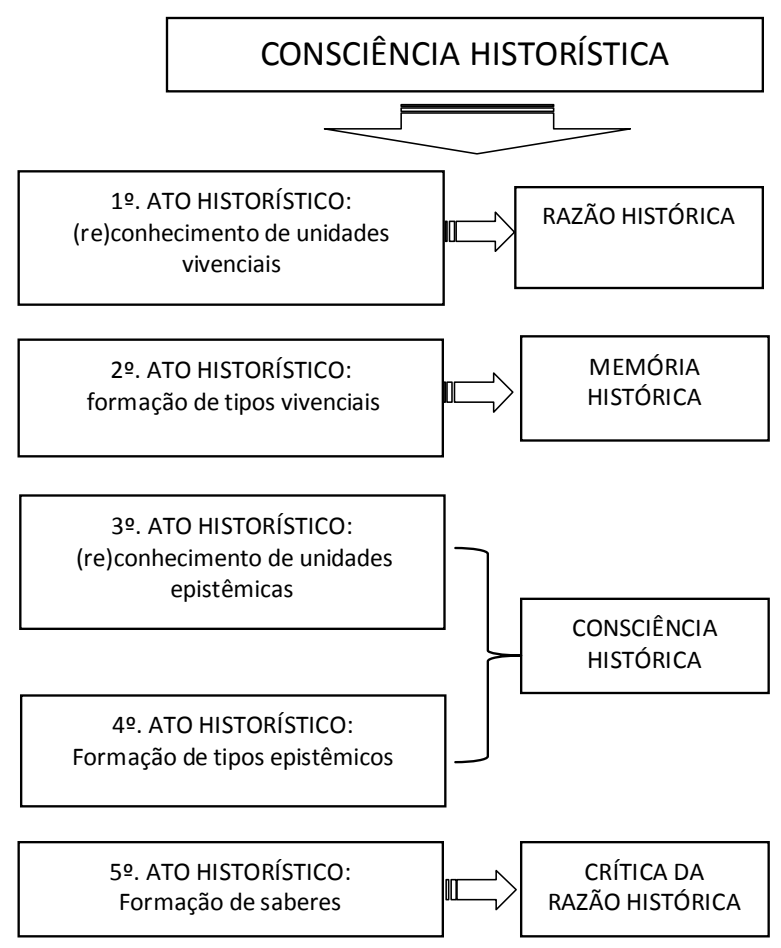

Fonte: o Autor 
A formação de saberes é, pois, no pensamento historístico, um ato educativo, de consciência histórica e de crítica da razão histórica, formadas pela própria razão histórica e memória histórica: não é um ato racionalista no sentido de Renato Descartes nem positivista no sentido de Augusto Comte.

Com o Método Historístico intenta-se diferenciar conhecimento de saber, retomando o pensamento de Augusto Boeckh (1785-1867): entender é conhecer o conhecido. Ou seja, entendimento é o conhecimento do conhecido, é reconstrução, revivência.

\section{REFERÊNCIAS}

1.Continentino AMA. A Alteridade no pensamento de Jacques Derrida: Escritura, Meio-Luto, Aporia. Tese (Doutorado em Filosofia) - Pontifícia Universidade Católica do Rio de Janeiro, Rio de Janeiro, 2006.216f. Rio de Janeiro: PUC, 2006

2.Derrida J. La Desconstrucción em las fronteras de la filosofia: la retirada de la metáfora. Barcelona: Paidós, 1993

$$
3 .
$$
A Escritura e a Diferença.

Trad. Maria Beatriz Marques Nizza da Silva. São Paulo: Perspectiva, 2002.

4. Gramatologia. Trad. Míriam Chnaiderman e Renato Janine Ribeiro. São Paulo: Ed. Perspectiva, 2008.

5.Dilthey W. Introducción a las ciencias del espiritu. 2. ed. Trad. Eugénio Imaz. México: Fondo de Cultura Económica. 1949

$$
6 .
$$
Psicologia y teoria del conocimiento. 2. ed. Trad. Eugénio Imaz. Espanhol. México: Fondo de Cultura Económica. 1951.
Com o Método Historístico reconhecese a importância do entendimento e busca-se impulsionar um novo patamar heurístico: o de formação de saber - ato criativo, construtivo, de vivência.

\section{CONCLUSÃO}

Historística é campo de formação de saberes. Dois possíveis usos do Método Historístico é de entendimento (conhecimento do já conhecido) e de formação de novos saberes, derivados ou não da contribuição de conhecimentos escritos (impressos) já postos.

7. La esencia de la Filosofia. 2. ed. Trad. Elsa Tabernig. Buenos Aires: Losada. 1952.

8. Teoria de la concepción del mundo. Trad. Eugénio Imaz. México: Fondo de Cultura Económica. 1954.

9. Crítica de la razón histórica. Trad. Carlos Moya Espí. Barcelona: Península. 1986

10. Faitanin P. A Gnosiologia tomista. http://www.aquinate.net/portal/Tomismo/Filosofia/t omismo-filosofia-a-gnosiologia-tomista.htm.

Acesso em 15 de agosto de 2013

11. Fernandes CR. Concepções de corpo na enfermagem dos anos noventa no Brasil: uma abordagem com Wilhelm Guillermo Dilthey. 2003. 179p. Dissertação (Mestrado em Enfermagem) Escola de Enfermagem, Universidade Federal de Minas Gerais, Belo Horizonte, 2003 
12.

Processo Saúde-Doença-Cuidado. Rio de Janeiro:

Águia Dourada. 2010

13. Fernandes CR, Nascimento ES. Historística: o campo dos fundamentos históricos da Ciência do Cuidado. Texto Contexto Enferm, Florianópolis, 2005 Out-Dez; 14(4):520-7

14. Foucault M. Arqueologia do saber. Trad. Luiz Felipe Baeta Neves. Rio de Janeiro: Forense Universitária, 2012

15. Ferrier JF. Institutes of metaphysics: The theory of knowing and being. Edinburgh: W. Blackwood, 1854
16. Jung CG. Psicologia e alquimia. 4. ed. Tad. Maria Luiza Appy, Margaret Makray, Dora Mariana R. F. da Silva. Petrópolis:Vozes. 1991.

17. Mora JF, Terricabras JM. Diccionario de Filosofia.Volume 2. Barcelona: Ariel, 1994

18. Nietzsche FW. Genealogia da moral: uma polêmica. São Paulo: Companhia das Letras,1998

19.Vico G. La Scienza Nuova. Milão: Rizzoli, 1959 